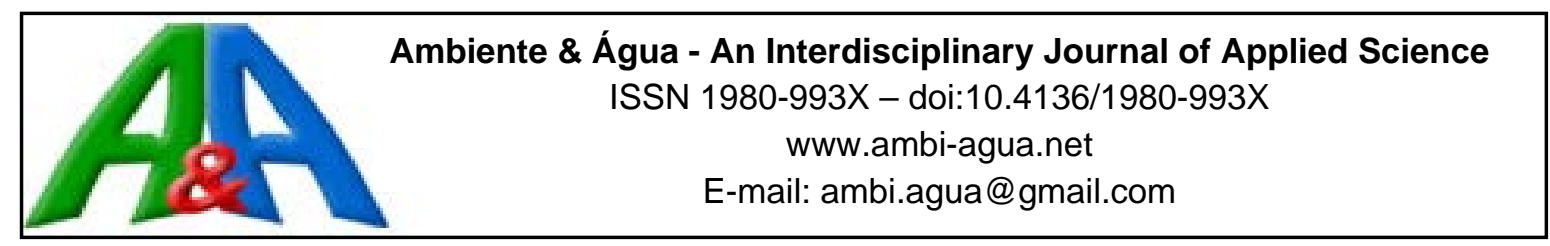

\title{
O conhecimento de produtores rurais do município de Arealva, SP, Brasil sobre as regras de uso dos agrotóxicos
}

\author{
doi:10.4136/ambi-agua.1922
}

Received: 28 Oct. 2016; Accepted: 08 Dec. 2016

\author{
Rafael de Melo Pereira ${ }^{1 *}$; Marialdo Correa de Araujo²; \\ Adriana Mascarette Labinas ${ }^{3}$ \\ ${ }^{1}$ Secretaria de Agricultura e Abastecimento do Estado de São Paulo \\ Centro de Fiscalização de Insumos e Conservação do Solo \\ ${ }^{2}$ Secretaria de Agricultura e Abastecimento do Estado de São Paulo \\ Escritório de Defesa Agropecuária de Pindamonhangaba \\ ${ }^{3}$ Universidade de Taubaté (UNITAU), Taubaté, SP, Brasil \\ Programa de Pós-Graduação em Ciências Ambientais \\ *Autor correspondente: e-mail: rafael.melo@cda.sp.gov.br, \\ marialdo.araujo@cda.sp.gov.br, alabinas@uol.com.br
}

\section{RESUMO}

Desde a década de 1970 as consequências ambientais do uso intensivo de agroquímicos despertaram os interesses e preocupações de técnicos, cientistas e agências governamentais, devido às possíveis contaminações causadas por essas substâncias. No entanto, um grande problema a ser considerado é o destino correto dos recipientes de agrotóxicos após a utilização dos produtos: um passivo resultante da intensificação do uso de pesticidas, anteriormente tratados como resíduos comuns, ou mesmo dispostos no ambiente. Este trabalho discutiu os resultados obtidos no estudo realizado na cidade de Arealva no Estado de São Paulo, abordando a importância do Sistema GEDAVE (Sistema de Gestão de Proteção Animal e Fitossanitária), desde o uso até o retorno de embalagens vazias de agrotóxicos, promovendo melhor monitoramento do uso e minimizando os riscos desses produtos. Observou-se que os agricultores conhecem as regras gerais que envolvem o uso racional de agroquímicos, no entanto, ainda têm dificuldades nas aplicações práticas quanto ao armazenamento na propriedade rural e na logística de devolução dos recipientes vazios. Assim foi observada a necessidade de encontro itinerante com frequência, como ferramenta que resolverá as dificuldades logísticas relatadas pelos produtores rurais.

Palavras-chave: defensivos agrícolas, embalagens vazias, logística reversa.

\section{The farmer's knowledge in Arealva, SP, Brazil about rules of agrochemicals use}

\section{ABSTRACT}

Since the 1970s, the environmental consequences of the intensive use of agrochemicals have aroused the interests and concerns of technicians, scientists, and government agencies because possible contaminations caused by these substances. However, a major problem to be considered is the correct destination of pesticide containers after the use of the products, a liability resulting from the intensification of the use of pesticides formerly treated as common 
waste, or even dumped in the environment. This paper discussed the results obtained in the work carried out in Arealva City in São Paulo State, approaching the importance of the GEDAVE System (Animal and Plant Protection Management System), from use to the return of empty packaging, promoting better monitoring of the use and minimizing risks of this products. It was observed that farmers know the general rules that involve the rational use of agrochemicals, however, they still have difficulties in the practical applications regarding the storage in the rural property and the logistics of returning empty containers. So it was observed the necessity of the itinerant gathering with frequency, like tool that will solve the logistic difficulties reported.

Keywords: chemical control, empty containers, reverse logistic.

\section{INTRODUÇÃO}

O uso de substâncias químicas para o controle de pragas e doenças na agricultura remonta aos primórdios da civilização. No Século XVI os chineses usavam o arsênico como inseticida e no Século XVII já se usava a nicotina, extraída das folhas de tabaco, com essa finalidade. Também são dessa época os primeiros registros de uso de mercúrio e sulfato de cobre como fungicidas (Silva e Fay, 2004).

A intensificação da busca sistemática por substâncias inorgânicas para a proteção de plantas aconteceu a partir do início do Século XX. Com a descoberta das propriedades inseticidas do organoclorado DDT (dicloro-difeniltricloretano) no período pós Segunda Grande Guerra Mundial, houve o início da chamada era moderna da agricultura, a partir da qual profundas mudanças nas técnicas de controle fitossanitário das culturas agrícolas garantiram a melhoria da produtividade das lavouras (Narloch, 2013).

Durante a década de 60, esse modelo agrícola se expandiu para os países do Terceiro Mundo, num processo que ficou conhecido como 'Revolução Verde' (Moreira et al., 2002), trazendo aumentos expressivos para a produtividade dos cultivos agrícolas. No Brasil, essa intensificação ganhou expressão na década de 1970, provocando grandes transformações na produção agrícola. Nessa época, a política de estímulo ao crédito rural, associada às novas tecnologias, impulsionou várias culturas, principalmente aquelas destinadas à exportação. Pacotes tecnológicos ligados aos financiamentos bancários estavam vinculados à aquisição de equipamentos e de insumos e entre esses insumos estavam os agrotóxicos, recomendados para o controle de pragas e doenças, como forma de ampliar o potencial produtivo das lavouras (Ruegg et al., 1991).

Entretanto, um problema que não costumava aparecer no cenário legal (Brasil, 1989) ou dos pacotes tecnológicos era a destinação correta das embalagens vazias de agrotóxicos: um passivo resultante da intensificação do uso dos produtos fitossanitários, que antes eram tratados como lixo comum, ou mesmo, largados no ambiente.

A destinação final das embalagens vazias de agrotóxicos prevista na Lei Federal 12.305, de 2 de agosto de 2010 (Brasil, 2010), determinou as responsabilidades específicas para cada elo da cadeia de produção e consumo de agrotóxicos no país, envolvendo agricultores, canais de distribuição e venda dos produtos comerciais, empresas fabricantes e o próprio poder público.

Para gerir todo este processo de destinação final das embalagens vazias de agrotóxicos, estabelecido pela Lei 9.974/00 (Brasil, 2000), os representantes da indústria fabricante criaram em 2001 o Instituto Nacional de Processamento de Embalagens Vazias -InPEV, entidade sem fins lucrativos que representa a indústria dos fabricantes de agrotóxicos, com a responsabilidade de conferir a correta destinação final às embalagens vazias daqueles 
produtos. Com isso foi instituída a logística reversa das embalagens vazias de agrotóxicos (Labinas e Araújo, 2016).

Segundo dados da Coordenadoria de Defesa Agropecuária - CDA, que é órgão de fiscalização da Secretaria de Agricultura do Estado de São Paulo, durante o ano de 2015 foram realizadas 87 fiscalizações em unidades de devolução de embalagens vazias no Estado, como resultado do desdobramento de outros processos de fiscalizações motivados, em sua maioria, pelo considerável número de detecções positivas em análises de resíduos de agrotóxicos enviados por outros órgãos fiscalizadores (São Paulo, 2015).

Com base nestas ocorrências, o Centro de Fiscalização de Insumos e Conservação do Solo - CFICS, da CDA, desencadeou uma série de atividades em algumas regionais, buscando melhorar o entendimento dos diversos setores que utilizam agrotóxicos, focando sempre a educação sanitária e a conscientização da importância da devolução das embalagens vazias.

Assim, o objetivo deste estudo foi avaliar o grau de entendimento de produtores rurais do município de Arealva (SP), quanto ao conhecimento sobre as diversas normas e leis que regem o trabalho e a utilização dos agrotóxicos e afins, especialmente, a destinação correta das embalagens vazias.

\section{MATERIAL E MÉTODOS}

No período de junho a setembro de 2016, foi elaborado e distribuído um questionário de leitura e análise contendo 26 perguntas fechadas, a 280 produtores rurais associados ao Sindicato Rural do município de Arealva, SP e a algumas dezenas de produtores rurais que, naquele período, visitaram a Casa da Agricultura do município.

Durante a atividade "Dia de Campo" realizado no mês de agosto de 2016, ao receber o questionário os produtores rurais receberam também um documento de preenchimento voluntário de solicitação de cadastro caso estivessem interessados em devolver embalagens vazias de agrotóxicos, necessitando, informar também o volume a ser devolvido.

As 26 questões que compunham o questionário visaram estimular a análise, por parte do produtor rural, das principais legislações vigentes sobre agrotóxicos e afins as quais foram agrupadas sob 6 temas: a) o volume e a origem das embalagens vazias informadas para a coleta itinerante durante o Dia de Campo ( questões de 1 a 3); b) a situação do armazenamento e dos depósitos de agrotóxicos e afins ( questões de 4 a 9); c) as normas para a correta devolução das embalagens vazias de agrotóxicos (questões de 10 a 20); d) as normas para o correto transporte das embalagens vazias (questões 21 e 22); e) as normas para a utilização racional e segura dos agrotóxicos e afins (questões 23 a 25); e, f) o conhecimento sobre o Sistema de Gestão de Defesa Animal e Vegetal - GEDAVE (questão 26).

Como as perguntas contidas no questionário eram fechadas, uma das estratégias utilizadas para avaliar o conhecimento e ao mesmo tempo instruir os produtores rurais foi que uma das respostas possíveis era, obrigatoriamente, o conteúdo descrito na legislação para cada um dos temas abordados, e assim o enunciado da questão de análise levava as opções verdadeiro - "V" ou falso - "F".

Desta forma, uma resposta certa dada pelo respondente seria, na verdade, o reconhecimento de uma situação prevista em lei.

\section{RESULTADOS E DISCUSSÃO}

Dos 280 questionários enviados aos produtores rurais e os demais disponibilizados ao público na Casa da Agricultura, obteve-se o retorno de apenas 65 (23\%) de questionários 
respondidos, logo, os resultados apresentados e discutidos na sequência farão referência, apenas, aos 65 que efetivamente responderam ao questionário.

Uma avaliação geral das Tabelas de 1 a 6 permitiu observar que para quase a totalidade das perguntas/enunciados respondidos pelos agricultores que participaram da avaliação, o número de respostas corretas foi maior que o número de respostas incorretas. Bernardo et al. (2015), trabalhando com produtores rurais do município de Tupã, entretanto, encontraram resultados diferentes, isto é: segundo esses autores 60\% dos participantes desconheciam ou eram indiferentes às informações referentes as embalagens vazias de agrotóxicos.

Os 65 produtores respondentes são originários de 12 bairros rurais do município de Arealva (Tabela 1), devolveram 3.498 embalagens vazias de agrotóxicos, sendo 2.969 unidades de embalagens rígidas e 529 unidades entre embalagens flexíveis e não laváveis. Em termos médios, equivaleria dizer que foram devolvidas cerca 53 embalagens vazias por produtor rural. Em que pese os produtores que margeavam o Rio Tietê, os quais produzem grãos não terem sido cadastrados nesta pesquisa, apenas para fins de comparação, observou-se que, dos registros existentes CDA o número médio de embalagens vazias devolvidas por esse grupo dessa região ultrapassou as 71 unidades.

Observa-se o registro de um número maior de embalagens de menor volume, ou seja até 1 litro, sendo devolvidas (Tabela 1), o que pode confirmar uma certa consonância dos produtores de Arealva com a tendência moderna da tecnologia de aplicação de defensivos, isto é: embalagens fracionadas, acondicionando volumes menores de defensivos, de forma a se evitar as sobras de produtos que podem ultrapassar o prazo de validade, danificar a matéria prima do vasilhame e, por conseguinte, prejudicar a logística reversa (Ferreira, 2011).

Tabela 1. Volumes de embalagens vazias cadastradas na coleta itinerante durante o Dia de Campo (Arealva, SP, Brasil).

\begin{tabular}{|c|c|c|c|c|c|c|c|c|}
\hline \multirow[b]{2}{*}{$\begin{array}{l}\text { Concentração do volume de embalagens a serem } \\
\text { devolvidas x bairros do município. }\end{array}$} & \multirow[b]{2}{*}{ Propriedades } & \multicolumn{4}{|c|}{ Até } & \multirow[b]{2}{*}{ Outras } & \multirow[b]{2}{*}{$\begin{array}{c}\text { Rígidas } \\
\text { Total }\end{array}$} & \multirow[b]{2}{*}{$\begin{array}{l}\text { Não } \\
\text { Laváveis }\end{array}$} \\
\hline & & $1 \mathrm{~L}$ & $5 \mathrm{~L}$ & $10 \mathrm{~L}$ & $20 \mathrm{~L}$ & & & \\
\hline $\begin{array}{l}\text { 1. Bairros que margeiam Rio Tietê: } \\
\text { Taquarussu, Marilandia, Corvo Branco, } \\
\text { Soturninha, Ribeirão Bonito. }\end{array}$ & 27 & 683 & 495 & 7 & 320 & 143 & 1.648 & 294 \\
\hline $\begin{array}{l}\text { 2. Bairros que não margeiam o Rio Tietê: } \\
\text { Córrego Fundo, Água grande, Matão, Jacuba, } \\
\text { Ribeirão Claro, Aparecidinha, Santa Izabel. }\end{array}$ & 38 & 1.047 & 131 & 14 & 13 & 116 & 1.321 & 235 \\
\hline $\begin{array}{l}\text { 3. Doze bairros rurais com produtores } \\
\text { cadastrados }\end{array}$ & 65 & 1.730 & 626 & 21 & 333 & 259 & 2.969 & 529 \\
\hline
\end{tabular}

Tratando-se do armazenamento e dos depósitos de defensivos nas propriedades rurais, a Tabela 2 deixou evidente o quanto os produtores respondentes se mostraram estar cientes das regras e aspectos legais que versam sobre as principais características de um depósito de agrotóxico. O menor percentual de acerto, com 72\%, foi para o enunciado onde se lia que um depósito deveria possuir embalagem de resgate de produtos avariados e, recipiente disponível para acondicionar material absorvente de possíveis vazamentos (como pó de serra, areia, etc). Este resultado pode indicar que as estratégias de comunicação das informações e recomendações técnicas e legais estão chegando aos produtores que, por sua vez, estão, em sua grande maioria, atendendo. 
Tabela 2. Situação do armazenamento e dos depósitos de agrotóxicos e afins em propriedades rurais de Arealva, SP, Brasil.

\begin{tabular}{ccc} 
Local coberto & & \\
para evitar o & Deposito de & Sem \\
acumulo de & agrotóxicos $(*)$ & Resposta \\
água da chuva & & \\
\hline
\end{tabular}

\begin{tabular}{llll}
\hline $\begin{array}{l}\text { 4. Onde devem ser guardadas as embalagens vazias de } \\
\text { agrotóxicos? }\end{array}$ & Verdadeiro (*) & $76,9 \%$ & $7,7 \%$ \\
\hline & Falso & $\begin{array}{c}\text { Sem } \\
\text { Resposta }\end{array}$ \\
\hline
\end{tabular}

5. Construção com material não combustível e piso impermeável com mureta interna para evitar vazamento de produtos para fora do deposito; porta sempre trancada, com $84,6 \%$ $4,6 \%$ $10,8 \%$ placa de advertência “CUIDADO VENENO”. (*)

6. Construção que favoreça a ventilação natural, com isolamento que impeça a entrada de amimais e aves. Ordenado com prateleiras e/ou estrados, distantes da parede $10 \mathrm{~cm}$; e, fiação elétrica sem emendas, com luz fria (fluorescente). (*)

7. O deposito deve possuir embalagem de resgate de produtos avariados e, recipiente disponível para acondicionar material absorvente de possíveis vazamentos (pó de serra, areia, etc). (*)

$72,3 \% \quad 9,2 \% \quad 18,5 \%$

8. Nunca reutilizar qualquer tipo de embalagem mesmo que secundária, pois as embalagens secundárias, como caixas de papelão, também apresentam obrigatoriedade para devolução. (*)

$76,9 \% \quad 6,2 \% \quad 16,9 \%$

9. No deposito de agrotóxicos não pode ser guardado nenhum outro produto, como ferramentas, ração, peças, entre outros. (*)

$84,6 \%$

$3,1 \%$

$12,3 \%$

Nota: Valores seguidos por asterisco (*) identificam as respostas corretas e os enunciados das solicitações de análise com opção para verdadeiro - "V” ou falso - "F” foram todas aquelas previstas em lei e, portanto, verdadeiras.

Para Bernardo et al. (2015), a comunicação entre os atores e a difusão das informações necessárias faz parte de todo esse processo de retorno das embalagens vazias de agrotóxicos, para que a logística reversa possa funcionar adequadamente e para que o Plano Nacional de Resíduos Sólidos tenha a aplicação desejada.

Se por um lado os produtores rurais mostraram saber o que deveria ser feito com as embalagens flexíveis dos agrotóxicos (Tabela 3), alcançando 61,5\% de respostas corretas, por outro lado, o baixo índice de acerto revelou que há falta de conhecimento para a destinação correta das embalagens não-laváveis e secundárias que, segundo Bernardo (2015), somadas, respondem por cerca de $15 \%$ de todo o material que circula no mercado.

Para as normas de devolução das embalagens vazias de agrotóxicos (Tabela 3), observouse um número de acertos superior a 52,3\% o que significaria dizer que ainda há espaço para investir na busca por índices de acertos ainda maiores, por exemplo: se, ao invés de 61,5\%, $100 \%$ dos respondentes pudessem afirmar que o pedido de coleta de produto vencido deveria ser formalizado ao fabricante que, por sua vez, deverá coletar o produto na propriedade, um número significativo de embalagens sairiam das propriedades e teriam garantido seu destino corretamente.

\section{IPABH}


Tabela 3. O grau de reconhecimento das normas para a devolução das embalagens vazias de agrotóxicos por parte de produtores rurais de Arealva (SP, Brasil).

\begin{tabular}{|c|c|c|c|}
\hline $\begin{array}{l}\text { Relacione os tipos de embalagens existentes e a forma do } \\
\text { condicionamento para devolução. }\end{array}$ & Verdadeiro & Falso & $\begin{array}{c}\text { Sem } \\
\text { Resposta }\end{array}$ \\
\hline $\begin{array}{l}\text { 10. Laváveis: Embalagens rígidas, tríplice lavadas, } \\
\text { inutilizadas, relacionadas por tamanho. }(*)\end{array}$ & $61,5 \%$ & $9,2 \%$ & $29,2 \%$ \\
\hline $\begin{array}{l}\text { 11. Não laváveis: Embalagens flexíveis e as de tratamento de } \\
\text { semente, acondicionadas em big-bag. }\left({ }^{*}\right)\end{array}$ & $33,9 \%$ & $37 \%$ & $29,2 \%$ \\
\hline \multirow[t]{2}{*}{$\begin{array}{l}\text { 12. Secundarias: Caixas de papelão. Tampas e lacres, } \\
\text { acondicionados em bag. }\left(^{*}\right)\end{array}$} & $33,9 \%$ & $37 \%$ & $29,2 \%$ \\
\hline & $\begin{array}{l}1 \text { ano após a data } \\
\text { da compra ou seis } \\
\text { meses após o prazo } \\
\text { de validade. }(*)\end{array}$ & $\begin{array}{l}\text { Qualquer } \\
\text { momento }\end{array}$ & $\begin{array}{c}\text { Sem } \\
\text { Resposta }\end{array}$ \\
\hline \multirow[t]{2}{*}{$\begin{array}{l}\text { 13. Qual prazo que o produtor tem para fazer a devolução das } \\
\text { embalagens vazias de Agrotóxicos? }\end{array}$} & $43,0 \%$ & $36,9 \%$ & $20 \%$ \\
\hline & Verdadeiro * & Falso & $\begin{array}{c}\text { Sem } \\
\text { Resposta }\end{array}$ \\
\hline $\begin{array}{l}\text { 14. Os postos de recebimento são mantidos por associações de } \\
\text { lojas agropecuárias e aceitam o recebimento apenas das } \\
\text { embalagens vazias dos produtos vendidos nas lojas que os } \\
\text { mantém. }\left({ }^{*}\right)\end{array}$ & $52,3 \%$ & $28 \%$ & $20 \%$ \\
\hline
\end{tabular}

15. As centrais de coleta são mantidas pelo inpEV (Instituto Nacional de Processamento de Embalagens Vazias) - através de associações como a ADIAESP, com recursos oriundos da reciclagem das embalagens vazias e de parcerias organizadas $58,5 \%$ $9,2 \%$ $32,3 \%$ com os fabricantes. $(*)$

16. Os produtos vencidos devem permanecer dentro do deposito de agrotóxicos, identificado e separados dos demais produtos. $(*)$

$73,6 \% \quad 11, \% \quad 15,4 \%$

17. O pedido de coleta do produto vencido deve ser formalizado ao fabricante que deverá coletar o produto na propriedade. $(*)$

$61,5 \% \quad 15 \% \quad 23,1 \%$

18. Caso o fabricante não recolha o produto no prazo indicado devera ser notificar através da Defesa Agropecuária. Após notificado o fabricante terá 120 dias para realizar a coleta; após o prazo e não recolhido será autuado. (*)

\begin{tabular}{|c|c|c|c|c|}
\hline & 1 ano $(*)$ & $\begin{array}{c}3 \\
\text { anos }\end{array}$ & $\begin{array}{c}5 \\
\text { anos }\end{array}$ & $\begin{array}{c}\text { Sem } \\
\text { Resposta }\end{array}$ \\
\hline \multirow{2}{*}{$\begin{array}{l}\text { 19. No momento da devolução, após todas as embalagens } \\
\text { serem vistoriadas o recebedor emitirá comprovante de } \\
\text { recebimento que deverá ser guardado pelo prazo de: }\end{array}$} & $29,2 \%$ & $3 \%$ & $\begin{array}{c}41,6 \\
\%\end{array}$ & $26,2 \%$ \\
\hline & $\begin{array}{l}\text { Todas as } \\
\text { embalagens } \\
\text { recolhidas }\end{array}$ & \multicolumn{2}{|c|}{$\begin{array}{l}\text { Apenas as } \\
\text { embalagens } \\
\text { contaminadas } \\
\text { e as flexíveis }\end{array}$} & $\begin{array}{c}\text { Sem } \\
\text { Resposta }\end{array}$ \\
\hline $\begin{array}{l}\text { 20. As Centrais de recolhimento de embalagens e os } \\
\text { fabricantes devem tomar as providencias para incinerar: }\end{array}$ & $64,6 \%$ & \multicolumn{2}{|c|}{$18,5 \%$} & $16,9 \%$ \\
\hline
\end{tabular}

Nota: Valores seguidos por asterisco $(*)$ identificam as respostas corretas e os enunciados das solicitações de análise com opção para verdadeiro - "V" ou falso - "F” foram todas aquelas previstas em lei e, portanto, verdadeiras. 
Com relação às normas para o transporte das embalagens vazias de agrotóxicos, o grande percentual de acertos contidos na Tabela 4, revelou o quanto está se diminuindo a exposição desnecessária de passageiros e condutores, aos possíveis resíduos contidos nas embalagens, especialmente nas não-laváveis. Segundo Pinheiro e Adissi (2007) e Rebelo et al. (2011) o risco às intoxicações com os agrotóxicos é dado em função da toxicidade do produto e do grau de exposição ao qual uma pessoa está submetida. Se a toxicidade é inerente à composição química do produto e não pode ser alterada, o grau de exposição pode ser maior ou menor em função, por exemplo, de atitudes e comportamentos e, portanto, pode ser mudado, especialmente com informação e treinamentos.

Tabela 4. O grau de reconhecimento das normas para o correto transporte das embalagens vazias de agrotóxicos por parte de produtores rurais de Arealva (SP, Brasil).

$\begin{array}{ccc}\text { Verdadeiro * } & \text { Falso } & \begin{array}{c}\text { Sem } \\ \text { Resposta }\end{array}\end{array}$

21. O condutor do veiculo é o responsável pelas embalagens que transporta e deve ter o cuidado de estar de posse das notas fiscais de compra relativas as embalagens transportadas. $(*)$

$72,3 \% \quad 12,3 \% \quad 15,4 \%$

22. Recomenda-se o transporte das embalagens vazias até o posto de recebimento em veículo utilitário com carroceria, sem o contato com pessoas e/ou outros produtos. $\left(^{*}\right)$

$80,0 \% \quad 4,6 \% \quad 15,4 \%$

Nota: Valores seguidos por asterisco $(*)$ identificam as respostas corretas e os enunciados das solicitações de análise com opção para verdadeiro - "V" ou falso - "F" foram todas aquelas previstas em lei e, portanto, verdadeiras.

A análise da Tabela 5, o que chamou à atenção foi o fato de $80 \%$ das respostas indicarem que seus respondentes reconhecem o período de carência como sendo o intervalo de tempo entre a última aplicação e o momento da colheita; consequentemente, indica, também, que caso este período seja desrespeitado, há a possibilidade da ocorrência de resíduos nos produtos colhidos. Este dado corrobora as últimas notícias publicadas na mídia (Agrolink, 2016) , onde a Agência Nacional de Vigilância Sanitária - ANVISA, analisando alimentos de todo o país (como cereais, frutas, legumes e verduras), entre 2013 e 2015, concluiu que quase 99\% das amostras não representavam risco à saúde da população, por não apresentarem resíduos de agrotóxicos acima do limite permitido por lei.

A orientação técnica é necessária para garantir as boas práticas por parte de todos os atores que interagem dentro do sistema de logística reversa das embalagens vazias de agrotóxico. Neste contexto, há que se mencionar o importante papel que Engenheiros Agrônomos e técnicos institucionais têm na prescrição e orientação da aplicação dos defensivos agrícolas (Tabela 5), reconhecidos nas respostas de mais de $83 \%$ dos que responderam o questionário.

Ainda que apenas 43\% (Tabela 6) dos respondentes declararam conhecer o Sistema GEDAVE, o sistema de gestão de defesa animal e vegetal da Secretaria de Agricultura e Abastecimento do Estado de São Paulo, é inegável o papel das instituições estaduais como agentes de educação, orientação e fiscalização tão importantes para o êxito do sistema de recolhimento e destinação correta das embalagens vazias de agrotóxico (Cometti e Alves, 2010). 
Tabela 5. O grau de reconhecimento das normas para uso racional e consciente de agrotóxicos por parte de produtores rurais de Arealva (SP, Brasil).

$\begin{array}{ccc}\text { Verdadeiro * } & \text { Falso } & \text { Sem } \\ \text { Resposta }\end{array}$

23. O EPI deve ser utilizado durante a aplicação e não pode ser guardado no deposito de agrotóxicos junto com os produtos e as embalagens vazias. $(*)$

$75,9 \% \quad 5,6 \% \quad 18,5 \%$

24. A colheita da produção poderá ser feita somente após o período de carência; caso esse período não seja respeitado o produto colhido poderá apresentar resultado positivo em $80,0 \% \quad 3,1 \% \quad 16,9 \%$ analise de resíduos. (*)

25. O Engenheiro Agrônomo poderá receitar produtos e sua dose, além de indicar a forma mais adequada de aplicação para cada cultura. $(*)$

$83,1 \% \quad 0 \% \quad 16,9 \%$

Nota: Valores seguidos por asterisco $(*)$ identificam as respostas corretas e os enunciados das solicitações de análise com opção para verdadeiro - "V” ou falso - "F" foram todas aquelas previstas em lei e, portanto, verdadeiras.

Tabela 6. Diagnóstico do questionário para o conhecimento Sistema GEDAVE - Gestão de Defesa Animal e Vegetal, manifestado pelos produtores pesquisados de Arealva (SP, Brasil).

\begin{tabular}{lcccc}
\hline & $\begin{array}{c}\text { Sim, pois faço a } \\
\text { declaração de vacina do } \\
\text { gado todo ano. }\end{array}$ & $\begin{array}{c}\text { Sim, mas não } \\
\text { possuo } \\
\text { senha. }\end{array}$ & Não & $\begin{array}{c}\text { Sem } \\
\text { Resposta }\end{array}$ \\
\hline $\begin{array}{l}\text { 26. Você conhece o sistema } \\
\text { GEDAVE? }\end{array}$ & $43,0 \%$ & $4,6 \%$ & $33,9 \%$ & $18,5 \%$ \\
\hline
\end{tabular}

Nota: Valores seguidos por asterisco $\left(^{*}\right)$ identificam as respostas corretas e os enunciados das solicitações de análise com opção para verdadeiro - "V" ou falso - "F" foram todas aquelas previstas em lei e, portanto, verdadeiras.

\section{CONCLUSÃO}

Observou-se que os produtores rurais foram capazes de reconhecer as normas gerais que envolvem o uso dos agrotóxicos, entretanto, ainda apresentam dificuldades nas aplicações práticas referentes ao armazenamento na propriedade rural e na logística de devolução das embalagens vazias. Por esta razão observou-se a necessidade da coleta itinerante com maior frequência, como proposta de ferramenta que venha a sanar as dificuldades observadas com a logística.

Com vistas a trabalhos futuros, sugere-se visitas técnicas às propriedades rurais para o diagnóstico e posterior acompanhamento das adequações de depósitos para armazenamento dos agrotóxicos e ordenamento para devolução das embalagens vazias. Espera-se que com o a sistematização do processo via sistema GEDAVE, a CDA possa melhorar o processo fiscal do recolhimento de embalagens vazias, gerando melhores dados para embasamento de futuras análises do assunto. 


\section{AGRADECIMENTOS}

A realização do trabalho que conduziu à elaboração deste artigo só foi possível devido à colaboração de um conjunto de pessoas, para as quais dirigimos nossos agradecimentos. Agradecimentos aos funcionários da CDA e em especial ao Engenheiro Marcelo Augustini Zonta (EDA Bauru), aos quais parabenizamos pela condução dos trabalhos junto às entidades parceiras.

Por fim, agradecimentos a toda equipe do Programa de Agrotóxicos da Coordenadoria de Defesa Agropecuária de São Paulo, que despenham trabalhos semelhantes por todo o Estado de São Paulo.

\section{REFERÊNCIAS}

AGROLINK. Alimento brasileiro é extremamente seguro para o consumo humano. 28 nov. 2106. Disponível em https://goo.gl/1uByWF Acesso em: 28 nov. 2016.

BERNARDO, C. H. C.; JÚNIOR, S. S. B.; MARQUES, M. D.; GOMES, S. C. V.; QUEIROZ, T. R. Percepção dos produtores rurais de Tupã, SP, sobre o processo de comunicação para execução da logística reversa de embalagens de agrotóxicos. Revista Observatório, v. 1, n. 3, p. 242-270, 2015.

BRASIL. Casa Civil. Lei $\mathrm{n}^{0}$ 7.802, de 11 de julho de 1989. Diário Oficial [da] União, 12 jul.1989.

BRASIL. Casa Civil. Lei n ${ }^{\text {9.974, de } 6}$ de junho de 2000. Diário Oficial [da] União, 7 jun. 2000.

BRASIL. Casa Civil. Lei nº 12.305, de 02 de agosto de 2010. Diário Oficial [da] União, 03 ago. 2010.

COMETTI, J. L. S.; ALVES, I. T. G. Responsabilização Pós-consumo e logística reversa: O Caso das Embalagens de Agrotóxicos no Brasil. Sustentabilidade em Debate, v. 1, n. 1, p. 13-24, 2010. http://dx.doi.org/10.18472/SustDeb.v1n1.2010.727

FERREIRA, A. M. A influência da legislação nos processos relacionados à logística reversa de embalagens vazias de agrotóxicos no município de São Mateus-ES. 2011. 64f. Trabalho de Conclusão de Curso (Graduação) - Universidade Federal do Espírito Santo, São Mateus, 2011.

INSTITUTO NACIONAL DE PROCESSAMENTO DE EMBALAGENS VAZIAS - INPEV. Reverse Logistic. 2016. Disponível em: http://www.inpev.org.br/index. Acesso em:: 21 jun. 2016.

LABINAS, A. M.; ARAUJO, M. C. de. Reverse logistics system and the role of government oversight for preservation of water and soil quality: the case of pesticide empty. Revista Ambiente \& Agua, v. 11, n. 4, p. 759 - 762, 2016. http://dx.doi.org/10.4136/ambiagua.1883.

MOREIRA, J. C. et al. Avaliação integrada do impacto do uso de agrotóxicos sobre a saúde humana em uma comunidade agrícola de Nova Friburgo, RJ. Ciência e Saúde Coletiva, v. 7, n. 2, p. 299-311, 2002. http://dx.doi.org/10.1590/S141381232002000200010 
NARLOCH, L. Guia politicamente incorreto do mundo. São Paulo: Casa da Palavra-Leya, 2013.

PINHEIRO, F. A.; ADISSI, P. J. Avaliação de risco ocupacional na aplicação manual de agrotóxicos. In: ENCONTRO NACIONAL DE ENGENHARIA DE PRODUÇÃOENEGEP, 27., 2007, Foz do Iguaçu. Anais... Foz do Iguaçu, 2007. p. 230-236.

REBELO, F. M.; CALDAS, E. D.; HELIODORO, V. D. O.; REBELO, R. M. Intoxicação por agrotóxicos no Distrito Federal, Brasil, de 2004 a 2007-análise da notificação ao Centro de Informação e Assistência Toxicológica. Ciências e Saúde Coletiva, v. 16, n. 8, p. 3493-502, 2011. http://dx.doi.org/10.1590/S1413-81232011000900017

RUEGG, E.F.; PUGA, F.R.; SOUZA, M.C.M.; ÚNGARO, M.T.S.; FERREIRA, M.S; YOKOMIZA, Y. et al. Impacto dos agrotóxicos sobre ambiente, a saúde e a sociedade. 2. ed. São Paulo: Ícone, 1991.

SÃO PAULO (Estado). Casa Civil. Relatório das atividades da administração, dados da fiscalização do uso e comércio de agrotóxicos. São Paulo, 2015

SILVA, C. M. de S.; FAY, E. F. Agrotóxicos \& Ambiente. Brasília: Embrapa Informação Tecnologia, 2004. 